\title{
Assessment of breast-feeding promotion in hospitals and follow-up survey of mother-infant pairs in Germany: the SuSe Study
}

\author{
Mathilde Kersting ${ }^{1, *}$ and Madeleine Dulon ${ }^{2}$ \\ ${ }^{1}$ Research Institute for Child Nutrition, Heinstück 11, D-44225 Dortmund, Germany: ${ }^{2}$ Department of Epidemiology \\ and Medical Statistics, School of Public Health, University of Bielefeld, \\ PO Box 100131, D-33501 Bielefeld, Germany
}

Submitted 22 August 2001: Accepted 14 November 2001

\begin{abstract}
Objective: To assess breast-feeding promotion in maternity hospitals and breastfeeding prevalences during the first year of life in mother-infant pairs in Germany. Design: Cross-sectional assessment of breast-feeding practices in a random sample of German maternity hospitals by use of a postal questionnaire. Follow-up of motherinfant pairs recruited in the participating hospitals to assess breast-feeding prevalences and infant feeding practices by use of a telephone interview 14 days after birth and food-frequency questionnaires mailed at the end of the 2nd, 4th, 6th, 9th and 12th month of life. Use of indicators for breast-feeding proposed by the World Health Organization (WHO) and the United Nations Children's Fund (UNICEF).

Setting: Nation-wide survey.

Subjects: One hundred and seventy-seven maternity hospitals, 1717 mother-infant pairs.

Results: There were wide variations in breast-feeding promotion in hospitals as evaluated by the practice of the ' 10 Steps to Successful Breastfeeding' given by WHO and UNICEF for certification as a 'Babyfriendly Hospital'. Some steps (3, 4, 8) were practised in about $90 \%$ of the hospitals, others (steps 7, 9) in only $10 \%$. Prevalences for exclusive (total) breast-feeding as defined by WHO were: 73\% (86\%) at discharge, $60 \%(85 \%)$ at 14 days, $42 \%(70 \%)$ at 2 months, $33 \%(59 \%)$ at 4 months, $10 \%(48 \%)$ at 6 months, $<1 \%(26 \%)$ at 9 months and $0(13 \%)$ at 12 months.

Conclusions: By use of indicators proposed by WHO and UNICEF, a differentiated insight into the breast-feeding situation in Germany has become possible. Moderate levels of breast-feeding promotion in hospitals resulted in almost satisfactory early breast-feeding prevalences but were not effective for long-term breast-feeding success in most mothers.
\end{abstract}

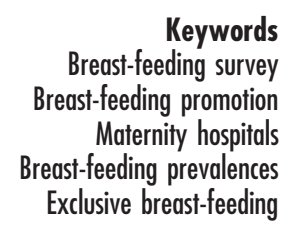

Keywords (ast-feeding survey Maternity hospitals reast-feeding prevalences Exclusive breast-feeding
Data on the situation of breast-feeding in a country are valuable for the evaluation of activities in breast-feeding promotion. While national data on breast-feeding are repeatedly collected in many developing countries, most industrialised countries do not assess breast-feeding systematically ${ }^{1}$. Methods and definitions used in breastfeeding epidemiology are not consistent at present ${ }^{1,2}$. Insight into breast-feeding promotion activities can be gained from the World Health Organization (WHO)/United Nations Children's Fund (UNICEF) Babyfriendly Hospital Initiative (BFHI), which has certified around 15000 hospitals world-wide as 'Babyfriendly'. Around 260 are situated in industrialised countries ${ }^{3}$.

In Germany, only sporadic data on breast-feeding have been available for the last 40 years ${ }^{4,5}$. Also, UNICEFcertified 'Babyfriendly Hospitals' are rare (1\%) in Germany. In 1994, a multisectoral National Committee for the Promotion of Breastfeeding was established appointed to the Federal Ministry of Health ${ }^{6}$. In 1997/98 the first nationwide survey on breast-feeding and infant nutrition, named the SuSe Study (Stillen und Säuglings-ernährung), was carried out on behalf of the German Nutrition Society, supported by the Federal Ministry of Health ${ }^{7}$.

For the SuSe Study, criteria of the BFHI in the form of the '10 Steps to Successful Breastfeeding, ${ }^{8}$ were used to assess breast-feeding promotion in randomly chosen maternity hospitals. Also, long-term breast-feeding practices were studied by use of WHO criteria 9 . No comparable studies have been reported. Here we present key findings from both assessments.

\section{Methods, materials and definitions}

\section{Hospitals}

From a list of the total of German maternity hospitals $(n=1120)$, a random sample of 360 hospitals was drawn. 
The chief doctors were contacted by letter and additionally by telephone if they did not answer in time. The maternity ward in 15 of the hospitals had been closed down. Of the eligible hospitals ( $n=345), 177$ hospitals (51\%) agreed to participate (Table 1). Participation included two duties for the staff: to fill out a 'hospital' questionnaire (175 hospitals) and to help with the recruitment of motherinfant pairs for the follow-up survey (177 hospitals). As a reason for refusal, the non-participating hospitals most often named 'no interest' (61\%) or 'lack of time' (26\%).

Only a few data are available to compare the study sample with the total of German hospitals. The study sample did not differ from the total with regard to annual birth rate ( 43 vs. $42 \%$ less than 500 births per year), regional distribution between the former politically separated Western (Federal Republic of Germany) and Eastern (German Democratic Republic) parts of Germany (83 vs. $82 \%)^{10}$ and the proportion of 'Babyfriendly Hospitals' (0.6 vs. 1.3\%).

The 'hospital' questionnaire, dealing with hospital structures and practices of breast-feeding management on the maternity ward, was filled out by the staff in charge. Besides items concerning e.g. choices of infant formula or dietary guidelines for lactating mothers, questions related to the '10 Steps' formed the main part of the questionnaire but were not directly named as such.

\section{Mother-infant pairs}

A specific 2-week period was assigned to each hospital for the recruitment of mother-infant pairs (Table 1). A total of 4352 mothers delivered during these periods. Some 22.6\% were excluded by the staff, about half of them due to exclusion criteria concerning the infant (birth weight $<2500 \mathrm{~g}$, gestational age $<37$ weeks, admission to neonatal unit) and the others concerning the mother (non-German speaking, no telephone at home). In addition, $1.7 \%$ were too late in submitting their written informed consent ${ }^{11}$.

The eligible mothers $(n=3294)$ were invited to participate by a letter handed out to them by the hospital staff. Of these, 1851 mothers (56.2\%) agreed to participate, and 1717 mothers (92.7\%) took part in the basic telephone interview $14( \pm 2)$ days after birth. Participants did not differ from non-participants with respect to their infant's gender, birth weight and delivery modus, but were better educated ${ }^{7}$.

The telephone interview 14 days after birth was designed to assess breast-feeding experiences since birth and breast-feeding prevalences at three time points: at birth, at discharge (median: 5 days after birth) and at the time of the interview.

To assess long-term breast-feeding prevalences, the same simple food-frequency questionnaire (FFQ) was mailed to the participants anew at the end of the 2nd, 4th, 6th, 9th and 12th month of infant life. The mother indicated the number of times or meals per day for breastmilk (including meals during the night), other milk (formula), non-milk fluids and (semi)-solids (named beikost) given to the infant. The recall referred to a typical one of the last few days. About 90\% of the participants returned the FFQ at the different time points during the first year of life (Table 1). A total of $80 \%$ of the participants had a complete follow-up of all five FFQs including a telephone interview after cessation of breast-feeding.

Infant feeding was categorised as proposed by $\mathrm{WHO}^{9}$ or by the German Breastfeeding Committee ${ }^{12}$ where appropriate (Table 2). In the German definitions, two additional feeding categories are named, i.e. breast-milk plus formula ('zwiemilch') and breast-milk plus formula plus beikost. We specified beikost according to the three different types of beikost meal recommended in Germany ${ }^{13}$.

Mothers who had ceased breast-feeding since the last FFQ were asked in another telephone interview to give their reasons, using pre-coded questions [time lag: mean (standard deviation (SD) 8.0 (0.6) weeks]. Mothers also reported the number of weeks for full breast-feeding and total breast-feeding retrospectively.

The SuSe Study is purely observational, non-invasive and

Table 1 Samples and methods for the assessment of breast-feeding in the SuSe Study

\begin{tabular}{|c|c|c|}
\hline Study sample & & Methods, criteria \\
\hline \multicolumn{3}{|l|}{ Maternity hospitals } \\
\hline Basis: German hospitals & $n=1120$ & \\
\hline Random sample & $n=360$ & \\
\hline Eligible sample & $n=345$ & \\
\hline Study sample & $n=177$ & ‘Hospital' questionnaire (March-May 1997) \\
\hline \multicolumn{3}{|l|}{ Mother-infant pairs } \\
\hline Basis: Deliveries (total) & $n=4352$ & Recruitment 14 days per hospital (March-May 1997) \\
\hline Eligible sample & $n=3294$ & $\begin{array}{l}\text { Inclusion: } \\
\text { - term, healthy newborn } \\
\text { - mother German speaking } \\
\text { - telephone at home }\end{array}$ \\
\hline Sample agreeing to participate & $n=1851$ & Written consent $<14$ days after birth \\
\hline Study sample & $n=1717$ & Telephone interview at $14( \pm 2)$ days after birth \\
\hline Follow-up & $\begin{array}{l}n=1540-1591 \\
\text { per FFQ }\end{array}$ & $\begin{array}{l}\text { Food-frequency questionnaire (FFQ) at } 2,4,6,9 \text { and } 12 \text { months ( } \pm 7 \text { days) after birth } \\
\text { Telephone interview after cessation of breast-feeding }\end{array}$ \\
\hline
\end{tabular}


Table 2 Definitions of breast-feeding categories as given by $\mathrm{WHO}^{9}$ and in Germany $(\mathrm{G})^{12}$

\begin{tabular}{lll}
\hline Exclusive breast-feeding & (WHO, G) & Only breast-milk, no other liquids or solids (except vitamin/mineral drops, syrups) \\
Predominant breast-feeding & (WHO, G) & Breast-milk and water or water-based drinks (including teas, fruit juice) \\
Full breast-feeding & (WHO, G) & Exclusive and predominant breast-feeding \\
Supplementary feeding & $(\mathrm{G})$ & Breast-milk and formula ('zwiemilch') \\
Supplementary feeding and beikost* & $(\mathrm{G})$ & Breast-milk and formula and beikost \\
Complementary feeding & $(\mathrm{WHO})$ & $\begin{array}{l}\text { Breast-milk and non-human milk and/or (semi)solids } \\
\end{array}$ \\
& $(\mathrm{G})$ & Breast-milk and beikost \\
(Total) Breast-feeding & $(\mathrm{WHO}, \mathrm{G})$ & (Any) breast-milk \\
Non breast-feeding & $(\mathrm{G})$ & Formula and/or beikost
\end{tabular}

*All foods and fluids except breast-milk and breast-milk substitutes (formula).

approved by the International Scientific Committee of the Research Institute for Child Nutrition. The written informed consent of each mother was obligatory for participation.

\section{Results}

\section{Hospitals}

The '10 Steps to Successful Breastfeeding' were practised to various extents in the hospitals, ranging from more than 90\% of hospitals for steps that encouraged breast-feeding on demand or early infant-breast contact to only $10 \%$ for steps that used alternative methods for supplementary feeding (Table 3). While 24-hour rooming-in was offered in $67 \%$ of the hospitals, it was practised by the majority of mothers in only $10 \%$ of the hospitals. Systematic information and training of the staff were common in about one-third of the hospitals.

\section{Breast-feeding prevalences}

Ninety-one per cent of the mothers started to breast-feed at birth (data not shown). At the day of discharge, 86\% were still breast-feeding, 73\% exclusively (Table 4). At 14 days after birth, the prevalence of exclusive breast-feeding had decreased considerably in favour of predominant breast-feeding. This means in practice that many mothers had started to feed tea to the baby. At the age of 4 (6) months, 59\% (48\%) were still breast-feeding, 33\% (10\%) of them exclusively. Supplementary feeding of formula was given to no more than about $10 \%$ of breast-fed infants at any age. In contrast, at least $20 \%$ of the infants received breast-milk complemented by beikost at the age of 6 and 9 months, named 'timely complementary feeding' by

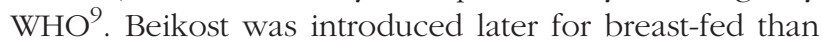
for non-breast-fed infants. In the second half of the first year of life, no more than 26\% (9 months) and 13\% (12 months) of the infants were breast-fed at all.

\section{Discussion}

\section{SuSe Study}

The SuSe Study is the first nation-wide study on breastfeeding in Germany. It was supported by federal institutions and taken as a data source for the National Committee for the Promotion of Breastfeeding. The structure of the study seems to be unique compared with other surveys in the literature since it combines an assessment of breast-feeding practices in hospitals with a one-year follow-up in mother-infant pairs, both based on

Table 3 Practising of the UNICEF '10 Steps to Successful Breastfeeding' in German hospitals ( $n=175 ; 100 \%)$

Step

Practice

Encourage breast-feeding on demand (Step 8) (\% of hospitals)

Help mothers initiate breast-feeding within half an hour after birth (Step 4)

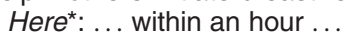

Inform all pregnant women about the benefits and management of breast-feeding (Step 3)

Foster the establishment of breast-feeding support groups and refer mothers to them on discharge from hospital (Step 10)

Here*: Refer mothers to breast-feeding support groups on discharge

Give newborn infants no food or drink other than breast-milk, unless medically indicated (Step 6)

Show mothers how to breast-feed and how to maintain lactation even if they should be separated from their infant

(Step 5)

Here $^{\star}$ : Show mothers how to breast-feed and document this in their records

Have a written breast-feeding policy that is routinely communicated to all healthcare staff (Step 1)

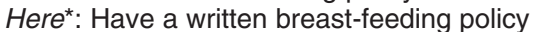

Train all healthcare staff in skills necessary to implement this policy (Step 2)

Practice rooming-in - allow mothers and infants to remain together -24 hours a day (Step 7 )

24-hour rooming-in generally offered

24-hour rooming-in practised by most mothers

Give no artificial teats or pacifiers to breast-feeding infants (Step 9)

Here*: Use alternative (finger, cup) feeding methods

* Wording of the questionnaire used in the SuSe Study. 
Table 4 Breast-feeding prevalences for different feeding categories at different times in the first year of life (\% of all mothers per time*)

\begin{tabular}{|c|c|c|c|c|c|c|c|}
\hline \multirow[b]{2}{*}{ Feeding categories } & \multicolumn{7}{|c|}{ Times and age of infants } \\
\hline & 5 days $†$ & 14 days & 2 months & 4 months & 6 months & 9 months & 12 months \\
\hline Exclusive breast-feeding (WHO‡, G§) & 73 & 60 & 42 & 33 & 10 & $<1$ & - \\
\hline Predominant breast-feeding (WHO, G) & 5 & 15 & 17 & 11 & 3 & $<1$ & $<1$ \\
\hline Full breast-feeding (WHO, G) & 78 & 75 & 59 & 44 & 13 & $<1$ & $<1$ \\
\hline Breast-feeding+formula (G) & 8 & 10 & 11 & 7 & $<1$ & - & - \\
\hline Breast-feeding+formula+beikost (G) & - & - & $<1$ & 4 & 9 & 6 & 4 \\
\hline Breast-feeding+beikost $(\mathrm{G})$ & - & - & $<1$ & 4 & 26 & 20 & 9 \\
\hline Complementary feeding (WHO) & 8 & 10 & 11 & 15 & 35 & 26 & 13 \\
\hline Total breast-feeding (WHO, G) & 86 & 85 & 70 & 59 & 48 & 26 & 13 \\
\hline Formula (G) & 12 & 15 & 28 & 20 & 2 & - & - \\
\hline Formula+beikost (G) & - & - & 2 & 21 & 50 & 74 & 879 \\
\hline Non breast-feeding (G) & 12 & 15 & 30 & 41 & 52 & 74 & 87 \\
\hline
\end{tabular}

${ }^{*} n=1717$ at 5 and 14 days; $n=1540-1591$ at $2,4,6,9$ and 12 months.

† At discharge, median: 5 days after birth; $2 \%$ missing ( $<1$ day's stay in hospital).

$\ddagger$ Definition by WHO, as described in Table 2 .

$\S$ Definition for Germany, as described in Table 2.

I Including 12\% receiving whole cow's milk instead of formula.

indicators for breast-feeding for international use. This combination allowed a differentiated insight into the situation of breast-feeding on a national level to be gained at not too high a cost.

A weakness of our study is the low participation rate of hospitals and mothers, resulting in self-selected samples for both study components. We cannot exclude that hospitals and mothers with particular interest in breastfeeding are over-represented among the study participants. Unfortunately, estimation of selection bias for breast-feeding patterns is hampered by lack of relevant data on the non-participants. The breast-feeding prevalences at discharge reported by the participating hospitals ${ }^{10}$ and by the participating mothers are roughly comparable with data from market research collected from mothers of infants all over Germany for the same year ${ }^{14}$. We assume that at least the early breast-feeding patterns of our sample mirror the situation in the whole country.

A strength of our study is the excellent long-term participation of mothers of about $90 \%$ until the end of the first year of life. The prospective instead of retrospective assessment of breast-feeding ${ }^{9}$ comprising all meals per day (and night) should have minimised recall bias.

\section{Breast-feeding promotion in bospitals}

Numerous observational and intervention studies worldwide have shown that breast-feeding management in maternity hospitals is critical for successful initiation and long-term duration of breast-feeding. Part of the scientific evidence is summarised in the '10 Steps to Successful Breastfeeding, $8,15,16$.

It is not known at present how the '10 Steps' are fulfilled in non-UNICEF-certified hospitals in European countries although these indicators could easily be used as a starting point for monitoring breast-feeding promotion. As the recommendations given by the National Breastfeeding Committee in Germany ${ }^{6}$ are close to the '10 Steps', it seemed logical to us to use them as an assessment tool for our survey.

We found values of between 10 and 90\% for the practice of the different steps. Our findings are based on selfreports of the hospital staff who might not always have been familiar with the background of the recommendations. Thus, misinterpretation of specific items of the questionnaire cannot be excluded. Some findings might have been different if we had done the inspections personally instead of using postal questionnaires. As an example, nearly all hospitals reported to practise breastfeeding on demand. In the sense of the recommendation breast-feeding on demand refers to 24-hour practice, but only two-thirds of the hospitals offered 24-hour roomingin. In the context of possible misinterpretation it is of interest that only about 30\% of the hospitals had regular training for the staff.

By the '10 Steps' specific obligations are assigned to the different people involved in the field of pre- and perinatal breast-feeding promotion, e.g. hospital administration, healthcare staff, mothers and society. Blame must not be put solely on the hospitals for their insufficient breastfeeding promotion. As an example, most mothers practised only daytime rooming-in although most hospitals offered the recommended 24-hour rooming-in. We do not know the reasons for the mothers' decision. We can only assume that they find it less demanding.

At present we cannot say whether our findings are typical for breast-feeding promotion in non-UNICEFcertified hospitals in other countries with a comparable sociodemographic background or could point to problems also existing in UNICEF-certified hospitals. In this respect it would be helpful to have more data from systematic re-assessments of 'Babyfriendly Hospitals'.

\section{Breast-feeding prevalences}

The situation of early breast-feeding found in our study, i.e. $91 \%$ at birth and $73 \%$ exclusively at discharge, already 
comes close to the aim of $75 \%$ for exclusive breast-feeding at discharge for 'Babyfriendly Hospitals', . Our figures for breast-feeding at discharge refer to the feeding habits for this day. Breast-feeding practices since birth might have included occasional bottle feedings, known or unknown to the mother, e.g. feeding at night for the infants of mothers practising daytime rooming-in.

In our study, the success of breast-feeding promotion in hospitals was obviously not upheld for long. Soon after discharge, the breast-feeding prevalences decreased rapidly and especially for exclusive breast-feeding.

Exclusive breast-feeding for 6 months is recommended by important authorities ${ }^{17-19}$. In field studies on large samples it is difficult to distinguish exclusive breastfeeding from predominant or full breast-feeding 9 . Moreover, different methods and definitions are in use in breast-feeding epidemiology ${ }^{2,20}$. With our questionnaires we asked explicitly for non-milk fluid consumption and found differences of up to $17 \%$ between exclusive and full breast-feeding depending on age (Table 4). As shown by this example, it has to be taken into account that some of the reported figures for exclusive breast-feeding might in reality refer to full breast-feeding.

Based on the figures for total breast-feeding in Germany for meaningful comparison, a steady increase since an historic low point in the middle of the 1970s becomes obvious ${ }^{4,5,14}$. The situation is comparable in other European countries and the USA but levels differ considerably $^{21,22}$. At present, around 70, 60 and 50\% of the infants in Germany are breast-fed at all at the age of 2, 4 and 6 months, respectively, and around 10\% at 12 months. Our findings compare well with the situation of breastfeeding in Italy ${ }^{23,24}$, but are much lower than in Scandinavia, e.g. in Sweden ${ }^{25}$. Improvements in breastfeeding promotion in hospitals based on the '10 Steps' could be effective in raising long-term breast-feeding success as shown by a recent large-scale systematic intervention study ${ }^{16}$. Additionally, in Germany more interdisciplinary breast-feeding support is necessary after discharge including paediatricians, obstetricians, midwives and breast-feeding support groups ${ }^{18}$.

Assessments of breast-feeding aimed at distinctions between different breast-feeding categories, i.e. different types of supplementary or complementary feedings, can easily be combined with an assessment of infant feeding practices in general. The latter is simplified in Germany because the recommended dietary schedule for the second half of the first year of life specifies only three different types of simple beikost meal. These can be given in the form of home-made or commercial beikost as the mother prefers ${ }^{13}$. We found that almost all infants receive the recommended meals at the recommended ages preferably as commercial products ${ }^{7}$. In total, the SuSe Study shows that, besides breast-feeding, in recent years infant feeding practices in general have also come closer to the recommendations in Germany.

\section{Conclusion}

Using indicators for breast-feeding as proposed by WHO and UNICEF, a differentiated insight into the situation of breast-feeding promotion in hospitals and long-term breast-feeding practices in mother-infant pairs is possible on a national level. For breast-feeding epidemiology and monitoring, more use of standardised definitions, e.g. from WHO and UNICEF, is necessary. Our data show that a merely moderate level of breast-feeding promotion in hospitals resulted in satisfactory breast-feeding prevalences for the hospital stay but this was not effective for long-term breast-feeding success in most mothers. Improved breast-feeding promotion in hospitals should be accompanied by interdisciplinary breast-feeding support begun in pregnancy and continued after discharge. In our study, the first weeks at home were the most critical period for continued breast-feeding success.

\section{Acknowledgements}

The SuSe Study was supported by the Federal Ministry of Health under Grant 423-7620-0/127.

\section{References}

1 World Health Organization. Global breastfeeding data collection: sources, prevalence, trends and association with global programmes. Personal communication, 2001.

2 Cattaneo A, Davanzo R, Ronfani L. Are data on the prevalence and duration of breastfeeding reliable? The case of Italy. Acta Paediatr. 2000; 89: 88-93.

3 http://www.babyfriendly.org.uk/indust.htm.

4 Kersting M, Koester H, Wennemann T, Wember T, Schöch G. Studies on breastfeeding 1981-1983 in 1500 mothers in Dortmund and Haltern. Parts I, II, III [in German]. Monatsschr. Kinderbeilkd. 1987; 135: 204-9, 247-52, 314-9.

5 Bergmann RL, Dudenhausen J, Bergmann E, Bergmann KE, Schmidt E, Bauer CP, et al. Infant feeding practices in Germany. Results of the multicenter cohort study on atopic diseases [in German]. Monatsschr. Kinderheilkd. 1994; 142 412-7.

6 http://www.bgvv.de/kommission.nsk/index.htm.

7 Dulon M, Kersting M. Breastfeeding and infant nutrition in Germany: the SuSe-Study [in German]. In: German Nutrition Society, ed. The Nutrition Report 2000. Frankfurt: German Nutrition Society, 2000; 81-95.

8 World Health Organization (WHO)/Wellstart International. Promoting Breastfeeding in Health Facilities. A Short Course for Administrators and Policy-makers. WHO/NUT/96.3. Geneva: WHO, 1996.

9 World Health Organization (WHO). Division of Diarrhoeal and Acute Respiratory Disease Control. Indicators for Assessing Breastfeeding Practices. Report of an informal meeting, 11-12 June 1991. WHO/CDD/SER 91.14. Geneva: WHO, 1991.

10 Dulon M, Kersting M. Breastfeeding promotion in German hospitals: results of the SuSe-Study [in German]. Franenarzt 2000; 41: 1248-55.

11 Dulon M, Kersting M, Schach S. Duration of breastfeeding and associated factors in Western and Eastern Germany. Acta Paediatr 2001; 90: 931-5. 
12 Springer S, Kersting M, Nehlsen E, Przyrembel H. Definitions of infant nutrition. Proposals from the National Committee on Breastfeeding Promotion in Germany [in German]. Sozialpädiatrie 1998; 21: 39-42.

13 Kersting M. Normal nutrition of infants. Food and meal based dietary guidelines [in German]. Monatsssch. Kinderheilkd. 2001; 149: 4-10.

14 IVE Research International. IVE Babymonitor. Hamburg: IVE Research International, 1999.

15 Heiberg Endresen E, Helsing E. Changes in breastfeeding practices in Norwegian maternity wards: national surveys 1973, 1982 and 1991. Acta Paediatr. 1995; 84: 719-24.

16 Kramer MS, Chalmers B, Hodnett ED, Sevkovskaja Z, Dzikovich I, Shapiro S, et al. Promotion of breastfeeding intervention trial (PROBIT): a randomized trial in the Republic of Belarus. J. Am. Med. Assoc. 2001; 285: 413-20.

17 Fifty-fourth World Health Assembly: Infant and Young Child Nutrition. WHA54.2, 18 May 2001.

18 American Academy of Pediatrics. Workgroup on breastfeeding. Breastfeeding and the use of human milk. Pediatrics 1997; 100: 1035-9.

19 Michaelsen KF, Weaver L, Branca F, Robertson A. Feeding and Nutrition of Infants and Young Children. Guidelines for the WHO European Region, With Emphasis on the Former Soviet Countries. WHO Regional Publication, European Series No. 87. Copenhagen: World Health Organization European Regional Office, 2000.

20 Aarts C, Kylberg E, Hornell A, Hofvander Y, Gebre-Medhin M, Greiner T. How exclusive is exclusive breastfeeding? A comparison of data since birth with current status data. Int. J. Epidemiol. 2000; 29: 1041-6.

21 Ryan AS. The resurgence of breastfeeding in the United States. Pediatrics Online 1997; 99. Available at www.pediatricsorg/cgi/content/full/99/4/e12.

22 Freeman V, van't Hof M, Haschke F, and the Euro-Growth Study Group. Patterns of milk and food intake in infants from birth to age 36 months: The Euro-Growth Study. J. Pediatr. Gastroenterol. Nutr. 2000; 31: (Suppl. 1) 76-85.

23 Riva E, Banderali G, Agostoni C, Silano M, Radaelli G, Giovannini M. Factors associated with initiation and duration of breastfeeding in Italy. Acta Paediatr. 1999; 88: 411-5.

24 Giovannini M, Banderali G, Agostoni C, Silano M, Radaelli G, Riva E. Epidemiology of breastfeeding in Italy. Acta Paediatr. Suppl. 1999; 430: 19-22.

25 Zetterström R. Foreword. Biol. Neonate 1998; 10: 80-3. 